\title{
REFRACTION CORRECTION FOR RADIO ECHO-SOUNDING OF ICE OVERLAIN BY FIRN
}

\author{
By L. A. RasmusSen
}

(Water Resources Division, U.S. Geological Survey, Tacoma, Washington 98402, U.S.A.)

\begin{abstract}
Radio-echo signals travel faster in firn than in ice, which affects the analysis of ice-mass thickness. If this effect is neglected, then the calculated thickness of an ice mass may be in error by an amount of the order of one-tenth of the firn thickness. An exact formulation is derived for the path of the signal through the firn and the ice. Explicit solutions are given for constant, linear, and quadratic profiles of the refractive index in the firn layer.
\end{abstract}

RÉSUMÉ. Correction de réfraction pour sondages par écho radar dans le cas de glace recouverte de névé. Les signaux d'échos radar voyagent plus rapidement dans le névé que dans la glace ce qui affecte l'analyse des épaisseurs de glace. Si cet effet est négligé, alors l'épaisseur calculee pour

The thickness of ice masses is of ten determined by radio echo-sounding, by using both surface-based and airborne systems. The development of this technology, for cold ice beginning in the $1960 \mathrm{~s}$ and for temperate ice beginning in the 1970s, has been summarized briefly by Brown and others (in press). In the published analyses, however, little account has been taken of the smaller value of the refractive index in the lower-density firn overlying the ice in accumulation zones, although Harrison (1970) supplied an approximate correction for the effect of firn for one special case. That correction, which assumed a homogeneous firn layer, is transformed here from an approximate to an exact formulation. Also given here is the exact formulation for an arbitrary vertical profile of refractive index, including explicit solutions for linear and quadratic profiles.

A ray with incident vertical angle $\theta$ in air is refracted at the air-ice boundary into a ray with vertical angle $\phi$ (Fig. 1) according to Snell's law,

$$
n_{\mathrm{i}} \sin \phi_{\mathrm{i}}=\sin \theta \equiv s
$$

in which the refractive index is $n_{\mathrm{i}}$ for ice and unity for air. Although the development is expressed here in terms of a horizontal air-firn boundary, it can readily be applied to the case in which that bouncary is inclined. In either case, the firn-ice toundary is assumed to be parallel to the air-firn boundary, and the $z$-axis is defined to be normal to them.

If the signal makes the round trip from $(0,0)$ to the reflecting point $(X, Z)$ at the ice-rock boundary. and back again in time $2 t$, then

$$
\left(\begin{array}{l}
x \\
z
\end{array}\right]=\frac{c t}{n_{\mathrm{i}}}\left[\begin{array}{c}
\sin \phi_{\mathrm{i}} \\
\cos \phi_{\mathrm{i}}
\end{array}\right)
$$

in which $c$ is the signal speed in air, and the factor $c t / n_{\mathrm{i}}$ equals the distance $R$ between $(X, Z)$ and $(0,0)$. For a specular reflection of the ray back to $(0,0)$, the reflecting surface at $(X, Z)$ must be sufficiently smooth and its slope must be $\mathrm{d} z / \mathrm{d} x=-\tan \phi_{\mathrm{i}}$.

When the ice is overlain by firn, determining the ray path is more complicated. For an arbitrary vertical profile la glace peut être affectée d'une erreur d'environ $10 \%$ de l'épaisseur du névé. Une formulation exacte en est déduite pour le trajet du signal à travers le névé et la glace. Des solutions explicites sont données pour des profils d'indice de réfraction constants, linéaire ou non à travers le névé.

ZUSAMMENFASSUNG. Refraktionskorrektur für RadarEcholotungen in firnbecktem Eis. Radar-Echosignale laufen in Firn schneller als in Eis, was Auswirkungen auf die Analyse von Eisdickenmessungen hat. Vernachlässigt man diesen Effekt, so kann die berechnete Eisdicke mit einem Fehler in der Grössenordnung von $10 \%$ der Firndicke behaftet sein. Eine exakte Formulierung lässt sich aus dem Weg des Signals durch Firn und Eis herleiten. Explizite Lösungen werden für konstante, lineare und quadratische Profile des Refraktionsindex in der Firnschicht angegeben.

$n(z / f)$ in the firn of thickness $f$, the horizontal distance at any depth $z \leqslant f$ is

$$
x(z)=\int_{0}^{z} \tan \phi(z) \mathrm{d} z=s \int_{0}^{z}\left[n^{2}(z / f)-s^{2}\right]^{-1 / 2} \mathrm{~d} z
$$

and the time consumed in traveling there from $(0,0)$ is

$$
\begin{aligned}
t(z) & =\frac{1}{c} \int_{0}^{z} n(z) \mathrm{d} z / \cos \phi(z) \\
& =\frac{1}{c} \int_{0}^{z} n^{2}(z / f)\left[n^{2}(z / f)-s^{2}\right]^{-1 / 2} \mathrm{~d} z .
\end{aligned}
$$

Because $n$ is a function of $z / f$, the integrals through the total firn thickness $f$ are proportional to $f$. This is significant because the magnitude of the effect of the firn is also proportional to $f$. This property of the integrals is revealed by introducing the simple change of variable $\bar{z}=z / f$ :

$$
\begin{aligned}
x_{f} \equiv x(f) & =s \int_{0}^{f}\left[n^{2}(z / f)-s^{2}\right]^{-1 / 2} \mathrm{~d} z \\
& =s f \int_{0}^{1}\left[n^{2}(\bar{z})-s^{2}\right]^{-1 / 2} \mathrm{~d} \bar{z}
\end{aligned}
$$

and

$$
\begin{aligned}
t_{f} \equiv t(f) & =\frac{1}{c} \int_{0}^{f} n^{2}(z / f)\left[n^{2}(z / f)-s^{2}\right]^{-1 / 2} \mathrm{~d} z \\
& =\frac{f}{c} \int_{0}^{1} n^{2}(z)\left[n^{2}(\bar{z})-s^{2}\right]^{-1 / 2} \mathrm{~d} \bar{z} .
\end{aligned}
$$


It is easily shown that the angle $\phi_{\mathrm{i}}$ eventually attained in the ice is the same as if the firn were not present. Thus, the reflecting point for the ray traveling through the firn and then through the ice is

$$
\left[\begin{array}{l}
x_{\mathrm{i}} \\
z_{\mathrm{i}}
\end{array}\right]=\left[\begin{array}{l}
x_{f} \\
f
\end{array}\right]+r_{\mathrm{i}}\left[\begin{array}{c}
\sin \phi_{\mathrm{i}} \\
\cos \phi_{\mathrm{i}}
\end{array}\right]
$$

in which $r_{\mathrm{i}}=\left(t-t_{f}\right) c / n_{\mathrm{i}}$ is the distance traveled below the firn. Both the point $(X, Z)$ and the point $\left(x_{\mathrm{i}}, z_{\mathrm{i}}\right)$, given by Equations (2) and (7), are functions through Equation (1) of $\theta$. As $\theta$ is varied, $(X, Z)$ generates the locus of the reflecting point if the effect of the firn is neglected, and $\left(x_{\mathrm{i}}, z_{\mathrm{i}}\right)$ generates the locus of the reflecting point if the effect of the firn is taken into account.

From Equations (1), (2), and (7) may then be obtained expressions for the firn corrections $\Delta X$ and $\Delta Z$ to be applied to the coordinates of the reflecting point $(X, Z)$ that would have been calculated by neglecting the firn

$$
\left[\begin{array}{l}
\Delta X \\
\Delta Z
\end{array}\right] \equiv\left[\begin{array}{l}
x_{\mathrm{i}} \\
z_{\mathrm{i}}
\end{array}\right]-\left[\begin{array}{l}
X \\
z
\end{array}\right]=\left[\begin{array}{l}
x_{f} \\
f
\end{array}\right]-\frac{c t_{f}}{n_{\mathrm{i}}}\left[\begin{array}{l}
\sin \phi_{\mathrm{i}} \\
\cos \phi_{\mathrm{i}}
\end{array}\right] .
$$

For airborne soundings, the critical ice angle $\phi=34.2^{\circ}$ cannot be exceeded. It corresponds to the limiting air angle $\theta=90^{\circ}$ when $n_{\mathrm{i}}=1.78$ is used in Equation (1). Thus, airborne soundings are capable of detecting points on the bed only where the bedrock slope is less than $\mathrm{d} z / \mathrm{d} x=\tan$ $34.2^{\circ}=0.679$. For surface soundings, with antennae in dielectric contact with the firn, steeper bedrock slopes can be detected.

The vertical profile $n(z / f)$ may be taken to vary quadratically (Fig. 1) from $n_{0}$ at the air-firn boundary to $n_{i}$ a the firn-ice boundary, where it has the derivative $\mathrm{d} n / \mathrm{d} z=0$. If the quadratic is a section of an ellipse,

$$
n(z / f)=\left[n_{0}^{2}+\left(n_{1}^{2}-n_{0}^{2}\right)(2-z / f) z / f\right]^{1 / 2}
$$

and the integrals may be directly evaluated, giving

$$
x_{f}=s f\left(n_{\mathrm{i}}^{2}-n_{\mathrm{o}}^{2}\right)^{-1 / 2} \sin ^{-1}\left[\left(n_{\mathrm{i}}^{2}-n^{2} \partial /\left(n_{\mathrm{i}}^{2}-s^{2}\right)\right]^{1 / 2}\right.
$$

and

$$
t_{f}=\frac{1}{2 c}\left[f\left(n_{\mathrm{o}}^{2}-s^{2}\right)^{1 / 2}+\left(n_{1}^{2}+s^{2}\right) x_{f} / s\right]
$$

Were the quadratic form without the exponent $\frac{1}{2}$ used, the profile would be a section of a parabola, but direct evaluation of the integrals would not be possible here. For all $0<z<f$, the elliptical profile gives a slightly higher $n$ than does the parabolic; for $1.20 \leqslant n_{0} \leqslant n_{i}=1.78$, the maximum difference is $\Delta n \approx N^{2} / 13$ at $z / f \approx(5-N) / 17$, in which $N=1.78-n_{0}$. The two profiles are indistinguishable at the scale of Figure 1, and the difference between them is probably small compared with the discrepancy between either of them and the actual profile in any particular firn layer. That the elliptical profile for $n_{0}=1.37$ and $f=120 \mathrm{~m}$ is not inappropriate is evidenced by the fact that when it is transformed to density, it agreed reasonably well (Fig. 2) with the density profile obtained at Site 2 in Greenland (Langway, 1967). The transformation was effected by a slight modification (from 0.851 to 0.867 ) of the constant of proportionality between $n-1$ and density used by Robin (1975, equation (1)), so that it would give $n=1.78$ at $0.9 \mathrm{Mg} / \mathrm{m}^{3}$.

A mathematical function with more than the one degree of freedom $\left(n_{0}\right)$ that the quadratics possess might more accurately represent an actual firn profile, but direct evaluation of the integrals of Equations (5) and (6) would likely not be possible. For an actual profile that cannot adequately be represented by an ellipse, it may be nece:sary to evaluate the integrals numerically, perhaps by using a piece-wise approximation of the $n$-profile.

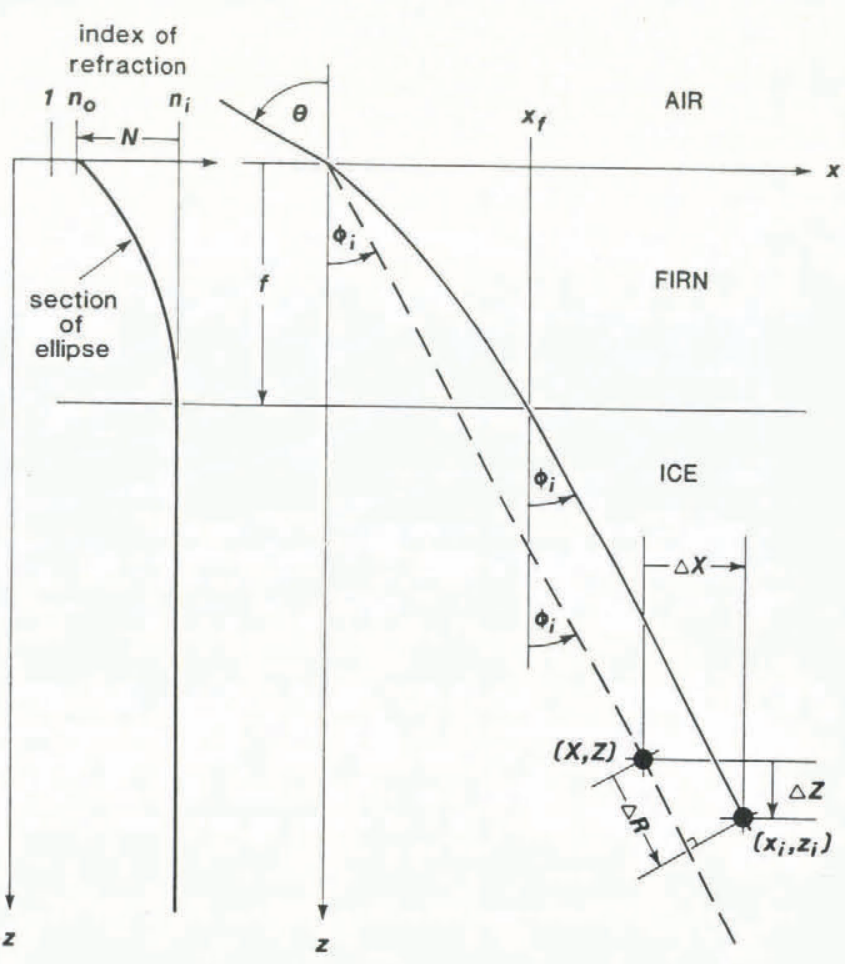

Fig. 1. Ray paths obtained by treating a glacier as consisting entirely of ice (dashed) and by accounting for refractive index following a quadratic profile in the firn and having constant value $n_{i}$ in the ice (solid). The firn-ice ray is distorted for diagrammatic clarity.

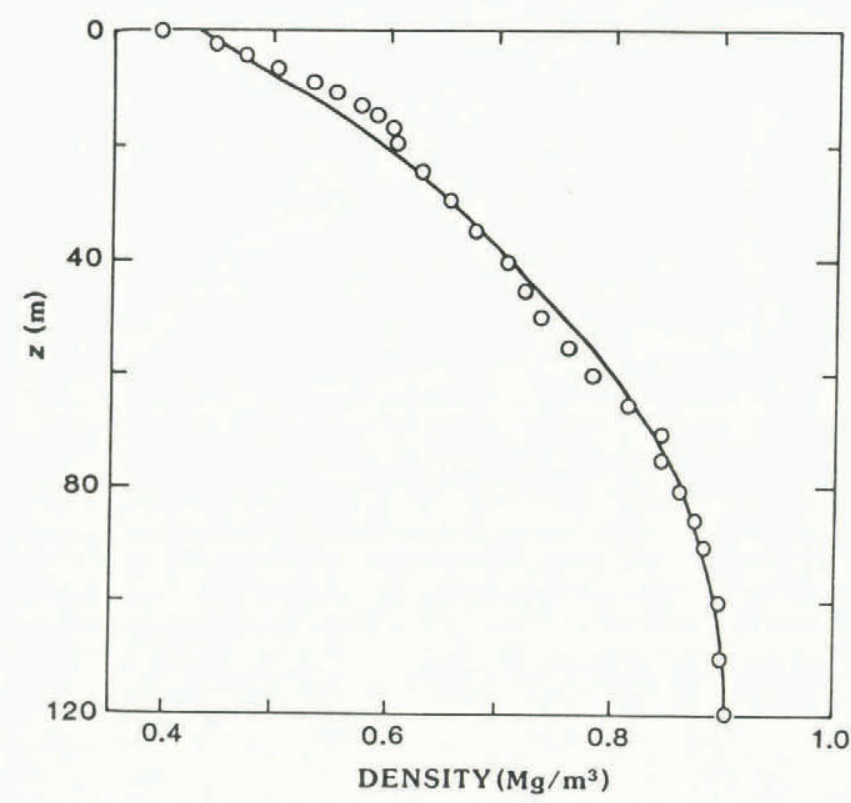

Fig. 2. Firn-density profiles. The circles are Site 2 in Greenland (Langway, 1967) as given in Paterson (1981, fig. 2.2). The curve is the $1.154(n-1)$ scaling of the elliptical profile of Equation (9) with $n_{0}=1.37$, a value chosen to give good agreement when thus transformed back to density.

The corrections $\Delta X$ and $\Delta Z$ obtained from the elliptical profile are shown in the form of $\Delta X / f$ and $\Delta Z / f$ in Figure 3 as functions of $n_{0}$ and $s$. The corrections are an order of magnitude smaller than $f$ and are both positive, except that $\Delta X=0$ when $s=0$. Depending on the accuracy of the radio echo-sounding results, and on the thickness and density of the firn layer, the correction may or may not be 


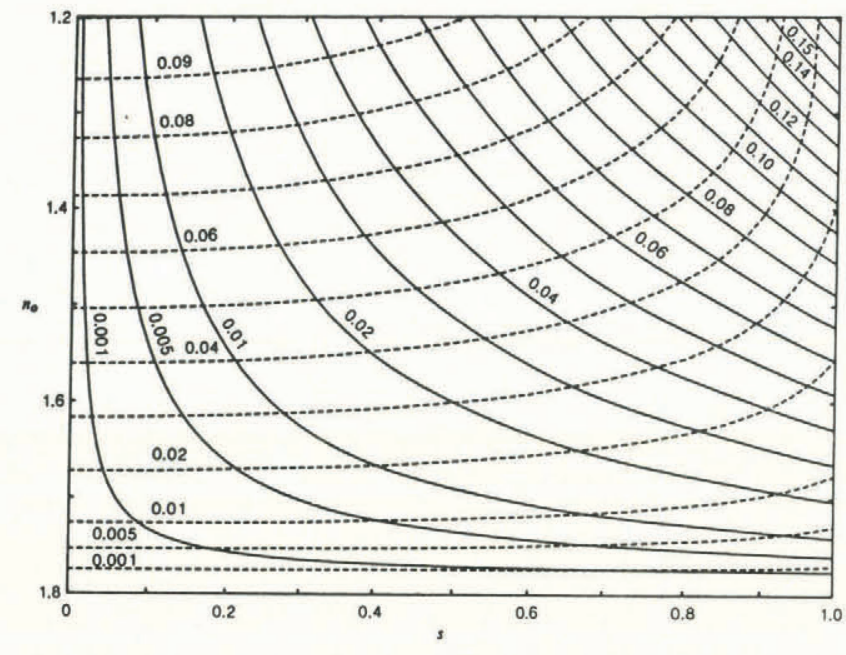

Fig. 3. Refraction corrections $\Delta X / f$ (solid) and $\Delta Z / f$ (dashed) as functions of $n_{o}$ and $s$, as given by equations (8) - (11) for $n_{i}=1.78$. For both fields the contour interval is 0.01 , except that contours for 0.005 and 0.001 are also shown. $\Delta X=\Delta Z=0$ along $n_{o}=n_{i}$, and $\Delta X=0$ along $s=0$.

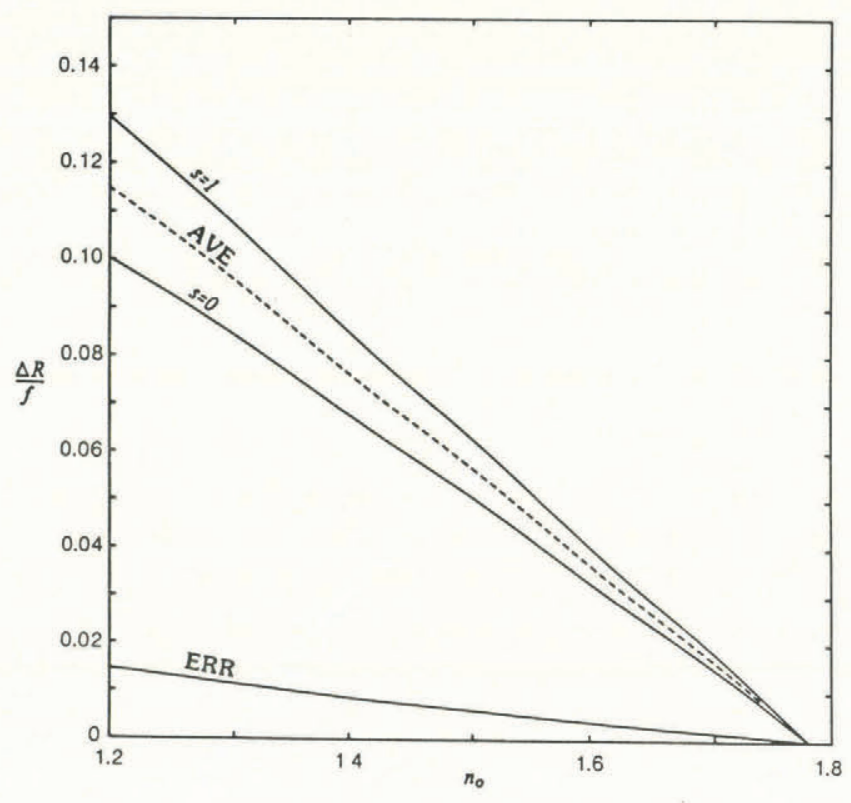

Fig. 4. Radius adjustment $\Delta R / f$ as a function of $n_{o}$ for roughly approximating firn-corrected reflection locus by a circle. Shown are the actual $\Delta R / f$ for $s \equiv \sin \theta=0,1$. Also shown are the average of these two (AVE) and the maximum error (ERR) in using the average.

significant. Direct measurement of glacier thickness by electrical resistivity soundings (Haeberli and Fisch, 1984) reveals an accuracy of within $5 \%$ in the radio echo-sounding of Grubengletscher, Switzerland.

When $s$ is not known for an echo received from a surface sounding, the reflecting point on the ice-rock boundary is known only to lie somewhere on a curve; on the circle with radius $R=c t / n_{\mathrm{i}}$ and center at $(0,0)$ if there is no firn, on a higher-order curve if firn is present. For use with data-analysis procedures that may assume a circular locus, because the effect of the firn was not taken into account, a correction in the forr. of an acjustment to the radius would be appropriate. The corrections $\Delta X$ and $\Delta Z$ do not depend on $R$, but the distance $r$ between $\left(x_{\mathrm{j}}, z_{\mathrm{i}}\right)$ and $(0,0)$ does. Therefore, the difference $\mathrm{r}-R>0$ is not a function of only $\Delta X$ and $\Delta Z$. However, because the corrections are small compared with $f$ and because $f$ is usually small compared with $r$, the distance $\Delta R$ is considered (Fig. 1). It is given by

$$
\Delta R=\Delta X \sin \phi_{\mathrm{i}}+\Delta Z \cos \phi_{\mathrm{i}} .
$$

The distance $\Delta R$ does not depend on $R$ but it does depend on $s$. Because it depends on $s$, the locus of the reflecting point is not circular. However, if the true locus is approximated by a circle with center at $(0,0)$ and with radius $R+\overline{\Delta R}$, then the error depends on the value of $\overline{\Delta R}$ used. It may be shown that $\Delta \mathrm{R}(s)$ increases monotonically from $\Delta R(0)$ to $\Delta R(1)$. Setting $\overline{\Delta R}=0.5[\Delta R(1)+\Delta R(0)]$ minimizes the maximum error $|\overline{\Delta R}-\Delta R(s)|$ over $0 \leqslant s \leqslant 1$, which is $0.5[\Delta R(1)-\Delta R(0)]$. The effect of the firt. is proportional to $f$ and is roughly proportional (Fig. 4 ; to $N=n_{\mathrm{i}}-n_{0}$. Thus, $N / 5$ approximates $\overline{\Delta R} / f$ with an accuracy of 0.001 , which is small compared with $0.5[\Delta R(1)-\Delta R(0)] / f$.

If $n(z / f)$ is taken to vary linearly from $n_{0}$ at the airfirn boundary to $n_{\mathrm{i}}$ at the firn-ice boundary,

$$
n(z / f)=n_{\mathrm{o}}+\left(n_{\mathrm{i}}-n_{\mathrm{o}}\right) z / f
$$

and the integrals become

$$
x_{f}=\frac{s f}{n_{\mathrm{i}}-n_{\mathrm{o}}} \ln \left[\frac{n_{\mathrm{i}}+\left(n_{\mathrm{i}}^{2}-s^{2}\right)^{1 / 2}}{n_{\mathrm{o}}+\left(n_{\mathrm{o}}^{2}-s^{2}\right)^{1 / 2}}\right]
$$

and

${ }^{t} f=\frac{1}{2 c}\left\{\left[n_{\mathrm{i}}\left(n_{\mathrm{i}}^{2}-s^{2}\right)^{1 / 2}-n_{\mathrm{o}}\left(n_{\mathrm{O}}^{2}-s^{2}\right)^{1 / 2}\right] f /\left(n_{\mathrm{i}}-n_{\mathrm{o}}\right)+s x_{f}\right\}$

which may be used with Equation (8) to obtain $\Delta X$ and $\Delta Z$ or with Equation (7) to obtain $\left(x_{\mathrm{i}}, z_{\mathrm{i}}\right)$. For the specia: case of firn with constant refractive index $n_{0}$, simple triangulation shows the reflecting point to be given by Equation (7) using $r_{\mathrm{i}}=\left(c t-n_{0}^{2} x_{f} / s\right) / n_{\mathrm{i}}$ for the distance traveled in the ice and $x_{f}=s f\left(n_{0}^{2}-s^{2}\right)^{-1 / 2}$; this formulation is consistent with that of Harrison (1970, equation (8)) based on the approximation of unit cosine for a small angle. For an actual firn profile that cannot be adequately represented by an ellipse, these results may be used incrementally to construct the ray path associated with either a piece-wise linear or a piece-wise constant approximation of the profile.

The firn correction is usually small compared with the firn thickness, which may justify neglecting the effect of the firn in some analyses. For other analyses the effect of the firn may be significant. Calculating the firn correction requires estimating the firn thickness and the vertical profile of the index of refraction in it. The errors in these estimates will affect the results but probably not as much as would neglecting the effect of the firn.

\section{REFERENCES}

Brown, C.S., and others. In press. Bed topography inferred from airborne radio-echo sounding of Columbia Glacier, Alaska, by C.S. Brown, L.A. Rasmussen, and M.F. Meier. U.S. Geological Survey. Professional Paper 1258-G.

Haeberli, W., and Fisch, W. 1984. Electrical resistivity soundings of glacier beds: a test study on Grubengletscher, Wallis, Swiss Alps. Journal of Glaciology, Vol. 30, No. 106 , p. $373-76$.

Harrison, C.H. 1970. Reconstruction of subglacial relief from radio-echo sounding records. Geophysics, Vol. 35, No. 6, p. $1099-1115$.

Langway, C.C., jr. 1967. Stratigraphic analysis of a deep ice core from Greenland. U.S. Cold Regions Research and Engineering Laboratory. Research Report 77.

Paterson, W.S.B. 1981. The physics of glaciers. Second edition. Oxford, etc., Pergamon Press. (Pergamon International Library.)

Robin, G. de Q. 1975. Velocity of radio waves in ice by means of a bore-hole interferometric technique. Journal of Glaciology, Vol. 15, No. 73, p. 151-59. 